\title{
Authors' reply: Vitamin D deficiency
}

Singapore Med J 2015; 56(10): 589 doi: 10.11622/smedj.2015157

Dear Sir,

We thank Lange and Cegolon for their letter. Regarding extraskeletal benefits, we agree that vitamin D potentially regulates many other cellular functions in addition to its role in calcium and bone homeostasis. The vitamin D receptor (VDR) is nearly universally expressed in nucleated cells and about $3 \%$ of the human/mouse genome is regulated by 1,25-dihydroxyvitamin D, the active form of vitamin D. Thus, the vitamin D endocrine system has a much broader spectrum of activity than calcium or bone homeostasis; in this regard, the vitamin D-VDR system resembles that of other nuclear receptor ligands, such as thyroid hormones. ${ }^{(1-3)}$

It is thus not unexpected that numerous studies have demonstrated an association between vitamin D deficiency and an increased risk of more than a dozen cancers (including that of the colon, prostate, breast and pancreas), autoimmune diseases (including types 1 and 2 diabetes mellitus, rheumatoid arthritis, Crohn's disease and multiple sclerosis), infectious diseases and cardiovascular diseases. ${ }^{(4)}$ However, most randomised controlled trials on the topic do not have an adequate dosing range to provide level I evidence on whether vitamin $\mathrm{D}$ can reduce the risk of these chronic diseases. ${ }^{(5)}$

A recent systematic review update by the United States' Agency for Healthcare Research and Quality ${ }^{(6)}$ summarised the evidence of the impact of vitamin D, alone or in combination with calcium, on selected health outcomes related to bone health, cardiovascular health, cancer, immune function, pregnancy and all-cause mortality. It also sought to identify the vitamin D assay methods and procedures used in interventional studies that assessed the effect of vitamin D administration on serum 25-hydroxyvitamin D [25(OH)D] concentrations, and to stratify key outcomes according to methods used to assay 25(OH)D concentrations. The review found that findings were inconsistent across studies for: (a) breast, colorectal and prostate cancer; (b) cardiovascular disease and mortality; (c) immune function; and (d) pregnancy-related outcomes. Few studies assessed pancreatic cancer and birth outcomes. Methods used to assay serum $25(\mathrm{OH}) \mathrm{D}$ in studies reporting on key outcomes diverged widely. The report concluded that the majority of the findings concerning vitamin $\mathrm{D}$, alone or in combination with calcium, were inconsistent on the health outcomes of interest. ${ }^{(6)}$

We therefore agree with the Endocrine Society task force's most recent vitamin $\mathrm{D}$ guideline, which emphasised the importance of preserving musculoskeletal health and preventing childhood rickets and adult bone disease. ${ }^{(4)}$ Vitamin D supplementation or treatment is usually inexpensive and cost-effective, particularly in treating medical entities such as osteoporosis, rickets and osteomalacia. It is less clear how much costs and resources are required for other preventive indications. We acknowledge the rapidly changing science in this field and that recommendations will likely need to be revised as the evidence grows.

We also agree with Lange and Cegolon that foods vary in their vitamin D content. Table I, which was taken from a review paper, shows the dietary, supplemental and pharmaceutical sources of vitamins $\mathrm{D}_{2}$ and $\mathrm{D}_{3} \cdot{ }^{(4)}$ The list is not exhaustive and is provided as a guide.

Table I. Natural sources of vitamins $D_{2}$ and $D_{3}$.

\begin{tabular}{ll}
\hline Source & Vitamin D content \\
\hline Salmon & \\
Fresh, wild (3.5 oz) & About 600-1,000 IU vitamin $\mathrm{D}_{3}$ \\
Fresh, farmed (3.5 oz) & About 100-250 IU vitamin $\mathrm{D}_{2}$ or $\mathrm{D}_{3}$ \\
Canned (3.5 oz) & About 300-600 IU vitamin $\mathrm{D}_{3}$ \\
Sardines, canned (3.5 oz) & About 300 IU vitamin $\mathrm{D}_{3}$ \\
Mackerel, canned (3.5 oz) & About 250 IU vitamin $\mathrm{D}_{3}$ \\
Tuna, canned (3.5 oz) & About 230 IU vitamin $\mathrm{D}_{3}$ \\
Cod liver oil (1 tsp) & About 400-1,000 IU vitamin $\mathrm{D}_{3}$ \\
Shiitake mushrooms & \\
Fresh (3.5 oz) & About 100 IU vitamin $\mathrm{D}_{2}$ \\
Sun-dried (3.5 oz) & About 1,600 IU vitamin $\mathrm{D}_{2}$ \\
Egg yolk & About 20 IU vitamin $\mathrm{D}_{2}$ or $\mathrm{D}_{3}$ \\
Exposure to sunlight, & About 3,000 IU vitamin $\mathrm{D}_{3}$ \\
ultraviolet B radiation & \\
(0.5 minimal erythemal dose) & \\
\hline
\end{tabular}

*About 0.5 minimal erythemal dose of ultraviolet B radiation would be absorbed after an average of 5-10 minutes of exposure (depending on the time of day, season, latitude and skin sensitivity) of the arms and legs to direct sunlight.

Yours sincerely,

Linsey Utami Gani ${ }^{1}$, Choon How $\underline{\text { How }}^{2}$

${ }^{1}$ Department of Endocrinology, ${ }^{2}$ Health and Care Integration, Changi General Hospital, Singapore. Linsey_gani@cgh.com.sg

\section{References}

1. Bouillon R. Vitamin D: From photosynthesis, metabolism and action to clinical applications. In: Jameson JL, De Groot LJ, eds. Endocrinology. Philadelphia: Saunders Elsevier, 2010: 1089.

2. Holick MF. Vitamin D deficiency. N Engl J Med 2007; 357:266-81.

3. Bouillon R, Carmeliet G, Verlinden L, et al. Vitamin D and human health: lessons from vitamin D receptor null mice. Endocr Rev 2008; $29: 726-76$.

4. Holick MF, Binkley NC, Bischoff-Ferrari HA, et al; Endocrine Society. Evaluation, treatment, and prevention of vitamin D deficiency: an Endocrine Society clinical practice guideline. J Clin Endocrinol Metab 2011; 96:1911-30.

5. National Research Council. Dietary Reference Intakes for Calcium and Vitamin D. Washington, DC: National Academies Press, 2011.

6. Newberry SJ, Chung M, Shekelle PG, et al. Vitamin D and Calcium: A Systematic Review of Health Outcomes (Update). Rockville, MD: Agency for Healthcare Research and Quality, 2014. 